\title{
Influence of Gemfibrozil on Sulfate Transport in Human Erythrocytes during the Oxygenation-Deoxygenation Cycle
}

\author{
E. TELLONE ${ }^{1}$, S. FICARRA ${ }^{1}$, R. SCATENA, ${ }^{2}$ B. GIARDINA ${ }^{2}$, A. KOTYK $^{3}$, A. RUSSO $^{1}$, \\ D. COLUCCI ${ }^{1}$, E. BELLOCCO' ${ }^{1}$, G. LAGANA', ${ }^{\text {, A. GALTIERI }}{ }^{1}$ \\ ${ }^{1}$ Department of Organic and Biological Chemistry, University of Messina, 98166 Messina, \\ ${ }^{2}$ C.N.R. Institute of Chemistry of Molecular Recognition and Institute of Biochemistry and Clinical \\ Biochemistry, Catholic University of Rome, I-00168 Rome, Italy and ${ }^{3}$ Institute of Physiology, \\ Academy of Sciences of the Czech Republic, Prague, Czech Republic
}

Received March 26, 2007

Accepted June 11, 2007

On-line July 26, 2007

\section{Summary}

The effects of gemfibrozil (GFZ), an antihyperlipidemic agent, on the anionic transport of the human red blood cells (RBC) during the oxygenation-deoxygenation cycle were examined. Gemfibrozil clearly plays a role in the modulation of the anionic flux in erythrocytes; in fact it causes a strong increment of anions transport when the RBCs are in the high-oxygenation state (HOS). Such an effect is remarkably reduced in the lowoxygenation state (LOS). With the aim of identifying the dynamics of fibrate action, this effect has been investigated also in human ghost and chicken erythrocytes. These latter, in fact, are known to possess a B3 (anion transporter or Band 3) modified at the cytoplasmic domain (cdb3) which plays a significant role in the metabolic modulation of red blood cells. The results were analyzed taking into account the well-known interactions between fibrates and both conformational states of hemoglobin i.e. the T state (deoxy-conformation) and the R state (oxy-conformation). The effect of gemfibrozil on anionic influx appears to be due to a wide interaction involving a "multimeric" Hb-GFZ-cdb3 macromolecular complex.

\section{Key words}

Gemfibrozil • Sulfate transport • Oxygenation - deoxygenation

\section{Corresponding author}

A. Kotyk, Institute of Physiology, Academy of Sciences of the Czech Republic, Vídeňská 1083, 14220 Prague 4, Czech Republic. E-mail: kotyk@biomed.cas.cz

\section{Introduction}

Many molecules of pharmacological interest, besides having mainly a positive and important role in clinical therapy, can interfere with some cellular processes determining alterations of normal cell functions. Fibric acid derivatives (clofibrate, bezafibrate and gemfibrozil), particularly effective in reducing the incidence of coronary heart diseases (Frick et al. 1987, Manninen et al. 1988) and in lowering low-density lipoprotein (Brown and Goldstein 1990b), are characterized by some important side effects such as an inhibitory activity of the mitochondrial respiratory chain, a significant production of oxygen free radicals (Chance and McIntosh 1995) and a strong allosteric interaction with hemoglobin.

In fact, these drugs permeating freely the erythrocyte membrane shift the oxygen equilibrium curve of human $\mathrm{Hb}$ to the right (Abraham et al. 1983, Perutz et al. 1983) lowering the affinity for oxygen more strongly than does the natural allosteric effector 2,3bisphosphoglyerate (BPG) (Hyde et al. 1984, Marden et al. 1988). The binding sites of these antihyperlipidemic effectors with hemoglobin are known for both conformational states of the molecule (Perutz et al. 1983, Lalezari et al. 1990, Poyart et al. 1994, Imai et al. 2002, Safo et al. 2002, Shibayama et al. 2002, Tsuneshige et al. 2002, Yonetani et al. 2002, Tsuneshige et al. 2004, Laberge et al. 2005).

It has been demonstrated that gemfibrozil and 
clofibrate induce a shift of the $\mathrm{O}_{2}$ dissociation curve (ODC) of erythrocytes toward the right (Scatena et al. 1995); moreover, the $p \mathrm{O}_{2}$ seems to represent a specific and selective signal that influences the anion transport function of band 3 through a molecular mechanism where the oxygen-linked T-R transition of $\mathrm{Hb}$ would play a key role (Galtieri et al. 2002, Russo et al. 2007). Thus the B3 cytoplasmic domain binds $\mathrm{Hb}$ through electrostatic interactions influenced by the oxygenation state of RBC (Chetrite et al. 1985, Salhany 1990); thus, the affinity of $\mathrm{Hb}$ for $\mathrm{cdb} 3$ is greater in the conformational $\mathrm{T}$ state than in R state with $K_{\text {ass }}$ approximately $10^{4} \mathrm{M}^{-1}$ and $10^{2} \mathrm{M}^{-1}$, respectively (Walder et al. 1984). In addition, B3 undergoes numerous interactions with other cytoskeletal proteins, such as ankyrin (Bennett 1985), protein 4.2 and 4.1 (Korsgren et al. 1986, Han et al. 2000), with the hemichromes and several glycolytic enzymes (Chu et al. 2006), such as aldolase (Low 1986), phosphofructokinase (Murthy et al. 1981), glyceraldehyde-3-phosphate dehydrogenase, lactate dehydrogenase (Kliman et al. 1980), pyruvate kinase (Campanella et al. 2005), glucose transporters (Jiang et al. 2006) protein tyrosine kinase p72 $2^{\text {syk }}$ (syk) (Harris et al. 1990, Harrison et al. 1994) and src p56/53 ${ }^{\text {lyn }}$ (lyn), and phosphatase protein PTP-1B (Zipser et al. 1996, Brunati et al. 2000).

These interactions are at the basis of molecular mechanisms which modulate cellular flexibility (Low et al. 1991, Goodall et al. 1994) and phosphorylation processes. In particular the phosphatase (PTP-1B), associated with the membrane, is responsible, through a redox system, for the low level of tyrosine phosphorylation normally present in these cells.

Moreover, the competition for $\mathrm{cdb} 3$ between $\mathrm{Hb}$ (in the $\mathrm{T}$ state) and glycolytic enzymes suggests a key role of $\mathrm{O}_{2}$ in modulating erythrocyte metabolism (Messana et al. 1996). In fact, at the level of tissues, the low $\mathrm{O}_{2}$ saturation state of the red blood cell switch on the interaction of deoxy-Hb with cdb3 determining the release and therefore the activation of glycolytic enzymes that channel the glucose-6-phosphate (G6P) toward ATP and BPG production. In contrast, in HOS erythrocytes the lower affinity between oxy-Hb and cdb3 makes accessible the interaction sites of $\mathrm{cdb} 3$ to glycolytic enzymes, the inhibition of which should reduce the glucose flux through the Embden-Meyerhof-Parnas pathway (EMP). As a consequence more G6P is available for the pentose phosphate pathway (PPP). In this way, $\mathrm{RBC}$ can satisfy the greater demand for NADPH, necessary at high oxygen saturation levels to counteract oxygen free radicals and ferrihemoglobin production (Giardina et al. 1995).

Based upon the fundamental role of $\mathrm{Hb}$ (connected with its oxygen-linked conformational transition T-R) in metabolic flux modulation and its known interaction with gemfibrozil, we tried to verify how much the presence of GFZ could influence the anionic transport of the human red blood cell, in the two extreme states of erythrocyte function, HOS and LOS. In addition, we tried to investigate the possible existence of metabolic changes caused by Hb-GFZ-cdb3 interactions.

\section{Methods}

\section{Material}

All reagents were from Sigma-Aldrich (St. Louis, MO, USA). Human erythrocyte samples were collected from informed healthy volunteers aged 30-50 years under the declaration that they had avoided any drug treatment at least one week before sample collection.

\section{Preparation of red blood cells}

Heparinized blood samples were washed three times with an iso-osmotic $\mathrm{NaCl}$ solution. During washings the white blood cells were discarded from the pellet. After washing the red blood cells were resuspended (hematocrit $3 \%$ ) in the incubation buffer (35 mM Na $2 \mathrm{SO}_{4}, 90 \mathrm{mM} \mathrm{NaCl}, 25 \mathrm{mM}$ HEPES [N-(2hydroxyethyl)-piperazine- $\mathrm{N}^{1}$-2-ethanesulfonic acid], $1.5 \mathrm{mM} \mathrm{MgCl} 2$ ), adjusted to $\mathrm{pH} 7.4$ or 7.3 and $310 \pm 20$ mOsmol per $\mathrm{kg}$, measured by an Osmostat OM-6020 apparatus (Daiichikagakuco, Kyoto, Japan).

In experiments performed with deoxygenated erythrocytes, samples were submitted to cycles of in vacuo deoxygenation and nitrogen (ultrapure) saturation at a pressure of $100 \mathrm{kPa}$. This treatment allowed us to obtain different levels of deoxygenation (from $15 \%$ up to $90 \%$ ), which were checked by determining hemoglobin saturation spectrophotometrically (Beckman DU 70 spectrophotometer) using the millimolar absorptivities reported by Zijlstra et al. (1991).

The buffer used to prepare deoxygenated erythrocytes was by $0.1 \mathrm{pH}$ unit lower than that used for oxygenated erythrocytes, in order to compensate for the Haldane effect taking place during the deoxygenation step (Labotka et al. 1984). Thus, after the deoxygenation procedure, the oxygenated and deoxygenated samples had an external $\mathrm{pH}$ different by no more than $0.03 \mathrm{pH}$ unit. 


\section{Preparation of $R B C$ ghosts}

Washed erythrocytes were lysed with iced hypotonic medium containing $5 \mathrm{mM}$ Tris and $5 \mathrm{mM} \mathrm{KCl}$. After hemolysis the hemoglobin and the intracellular contents were eliminated by centrifugation. The membranes were resealed by incubation at $37{ }^{\circ} \mathrm{C}$ for one hour with a closing buffer. The resealed ghosts were suspended in the same buffer used for sulfate transport in entire red blood cells.

\section{Kinetic measurements}

Cells were incubated in the above incubation buffer at $25{ }^{\circ} \mathrm{C}$, under different experimental conditions. At several time intervals, 10 micromoles of the stopping medium SITS (4-acetamido-4'-isothiocyanostilbene-2,2' disulfonic acid) were added to each test tube containing 5 $\mathrm{ml}$ of the red blood cell suspension. Cells were then separated from the incubation medium by centrifugation (J2-HS Centrifuge, Beckman, Palo Alto, CA, USA) and washed three times at $4{ }^{\circ} \mathrm{C}$ with a sulfate-free medium to remove the sulfate trapped outside. After the last washing the packed cells were lysed with perchloric acid (4\%) and distilled water $(2.8 \mathrm{ml}$ final volume). Lysates were centrifuged for $10 \mathrm{~min}$ at $4000 \times \mathrm{g}\left(4^{\circ} \mathrm{C}\right)$ and membranes were separated from the supernatant. Sulfate ions were precipitated from the supernatant by adding $1 \mathrm{ml}$ of glycerol/distilled water mixture $(1: 1, \mathrm{~V} / \mathrm{V}), 0.5 \mathrm{ml}$ of $4 \mathrm{M}$ $\mathrm{NaCl}$ and $1 \mathrm{M} \mathrm{HCl}, 0.5 \mathrm{ml}$ of $1.23 \mathrm{M} \mathrm{BaCl}_{2} \cdot 2 \mathrm{H}_{2} \mathrm{O}$ in order to obtain a homogeneous barium sulfate precipitate. The absorbance of this suspension was measured at $350-425 \mathrm{~nm}$.

Using a calibrated standard curve, obtained by measuring the absorbance of suspensions obtained from solutions containing known sulfate amounts, the sulfate concentration was determined (Romano et al. 1998). Experimental data of sulfate concentration as a function of the time of incubation were analyzed by best fitting procedures according to the following equation:

$c(t)=c_{\infty}\left(1-\mathrm{e}^{-k t}\right)$ where $\mathrm{c}(t)$ represents sulfate concentration at time $t, c_{\infty}$ intracellular sulphate concentration at equilibrium, and $k$ the rate constant of sulphate influx.

\section{Determination of PTP activity}

PTP activity was defined using $p$-nitrophenyl phosphate ( $p$-NPP) as substrate. Briefly, membranes were suspended in $25 \mathrm{mM}$ Hepes buffer of $\mathrm{pH} 7.3$, containing $0.1 \mathrm{mM}$ PMSF, $20 \mathrm{mM} \mathrm{MgCl} 2$ and $15 \mathrm{mM} p$-NPP, and incubated at $37^{\circ} \mathrm{C}$ for $30 \mathrm{~min}$. After centrifugation, the release of $p$-nitrophenol was measured in the supernatant at $410 \mathrm{~nm}$.

\section{Statistical analysis}

Differences were analyzed with a two-tailed Student's t-test for unpaired data. Upon occurrence the group means were compared by analysis of variance (ANOVA) followed by a multiple comparison of means by Dunnet test. The results are expressed as means \pm S.D. $P<0.05$ was considered significant.

\section{Results}

Here we study the gemfibrozil effects on the anionic transport of human erythrocytes in two extreme conditions represented by: HOS (about $90 \%$ of saturation) and LOS (about $15 \%$ of saturation).

Table 1. Rates of sulfate transport measured in oxygenated and deoxygenated human red blood cells with and without gemfibrozil. ( $p<0.05$ was considered significant).

\begin{tabular}{llll}
\hline & $\begin{array}{l}\text { Rate constant } \\
\left(\mathbf{m i n}^{-\mathbf{1}}\right)\end{array}$ & $\begin{array}{l}\text { Rate constant } \\
\left(\mathbf{m i n}^{-\mathbf{1}} \mathbf{)}\right.\end{array}$ & $\boldsymbol{p}$ \\
\hline Medium composition & Oxygenated & Deoxygenated & HOS vs. LOS \\
Control & $0.012 \pm 0.0026(n=4)$ & $0.005 \pm 0.0006(n=5)$ & 0.0007 \\
0.5 mM gemfibrozil & $0.010 \pm 0.0003(n=3)$ & $0.005 \pm 0.0006(n=5)$ & $7.134 \times 10^{-6}$ \\
1 mM gemfibrozil & $0.020 \pm 0.0075(n=3)$ & $0.005 \pm 0.0018(n=5)$ & 0.0046 \\
1.5 mM gemfibrozil & $0.041 \pm 0.0015(n=4)$ & $0.006 \pm 0.0016(n=3)$ & 0.0041 \\
3 mM gemfibrozil & $0.052 \pm 0.0014(n=4)$ & $0.008 \pm 0.0014(n=3)$ & 0.0036 \\
5 mM gemfibrozil & $0.051 \pm 0.0061(n=3)$ & $0.008 \pm 0.0011(n=3)$ & 0.0002 \\
$10 \mathrm{mM}$ gemfibrozil & $0.052 \pm 0.0080(n=3)$ & $0.008 \pm 0.0021(n=3)$ & 0.0028 \\
\hline
\end{tabular}




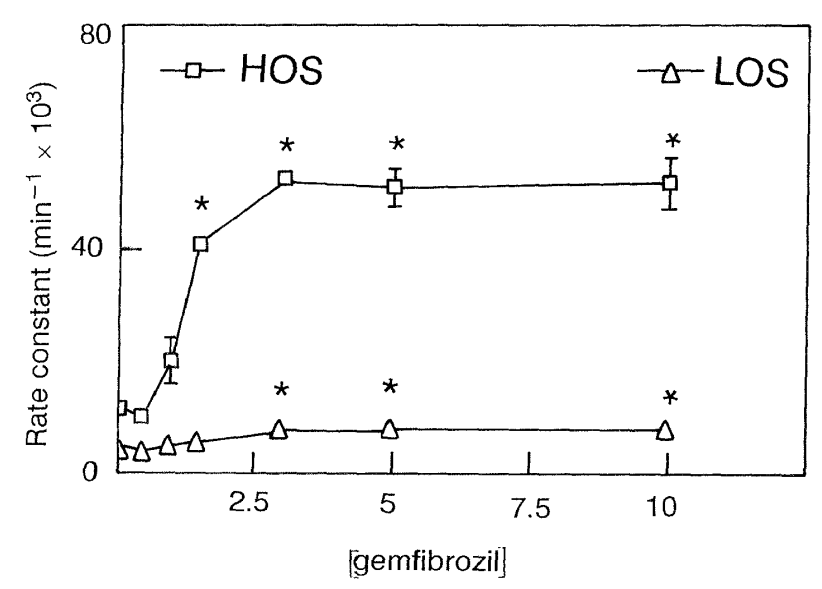

Fig. 1. Dose-dependent gemfibrozil-induced modifications of the rate of sulfate transport measured in oxygenated (HOS) and deoxygenated (LOS) human red blood cells. $(* *=p<0.01$ versus vehicle, by ANOVA).

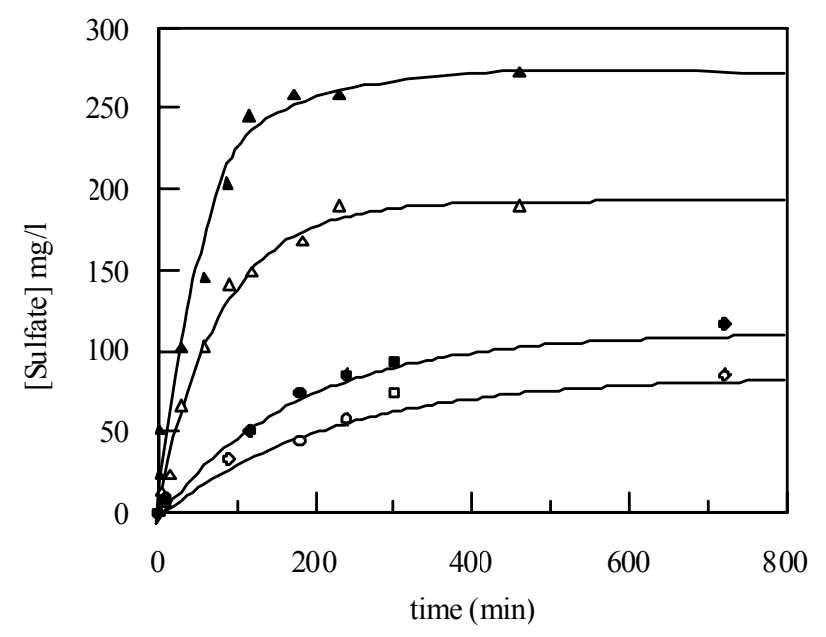

Fig. 2. Sulfate concentration $(\mathrm{mg} / \mathrm{l})$ determined in red blood cell lysates at different incubation times. Results of a typical experiment performed by incubating the erythrocytes with (closed symbols) and without (open symbols) $3 \mathrm{mmol} / \mathrm{l}$ of gemfibrozil under high (triangles) and low (circles) oxygen pressures. Curves were obtained by fitting experimental data with the equation $c(t)=c_{\infty}\left(1-\mathrm{e}^{-k t}\right)$. See Methods for further experimental details.

As shown in Table 1 and Fig. 1 the mean of rate constant values determined for sulfate influx in HOS and LOS erythrocytes incubated with increasing concentrations of gemfibrozil reveal that the fibrate influences the anionic exchange kinetics under both conditions. More specifically the drug increases B3 activity proportionally to its concentration up to $3 \mathrm{mM}$; concentration levels higher than this value do not produce any further increase of B3 activity.

Fig. 2 shows the fibrate effect on the anionic transport kinetics in cells incubated with a gemfibrozil concentration of $3 \mathrm{mM}$. It may be seen that the drug

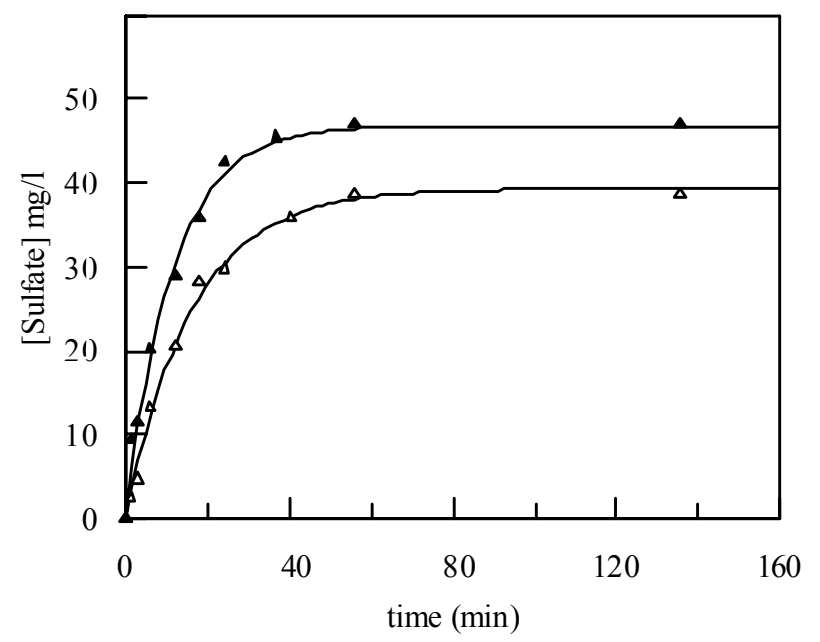

Fig. 3. Sulfate concentration $(\mathrm{mg} / \mathrm{l})$ determined in ghost lysates at different incubation times. Results of a typical experiment performed by incubating the erythrocytes with (closed symbols) and without (opf symbols) $3 \mathrm{mmol} / \mathrm{l}$ of gemfibrozil. Curves were obtained by fitting experimental data with the equation: $c(t)=c_{\infty}\left(1-\mathrm{e}^{-k t}\right)$. See Methods for further experimental details.

modulation is higher in HOS erythrocytes (rate constant $0.052 \mathrm{~min}^{-1}$ and $0.012 \mathrm{~min}^{-1}$, respectively, for treated and untreated RBCs) than in LOS (rate constant $0.008 \mathrm{~min}^{-1}$ and $0.005 \mathrm{~min}^{-1}$, respectively, with and without GFZ). Since it is possible that $\mathrm{O}_{2}$ affects the activity of other transport systems in red blood cells we carried out a set of experiments on integral cells and on ghosts pretreated with SITS, a specific inhibitor of B3 activity. Under these experimental conditions no sulfate transport was observed (data not shown); hence, we excluded the contribution of other transport systems in our observations.

Interestingly, we find that the fibrate effect on the anion influx is also present in particular structures, such as ghosts. These results are shown in Fig. 3 where a small increment of B3 activity in ghosts compared to the intact RBC can be noticed; this is due to the absence of several cytoplasmic factors that modulate the anion transport among which $\mathrm{Hb}$ is the most representative. However, the persistence of gemfibrozil effect on the sulfate transport led us to investigate the nature of the drug action on the anionic channel.

A possible interaction path between the drug and B3 could involve a phosphorylative action toward Tyr 8, 21, 359 and 904; hence we tested the PTP-1B activity which is not affected by $3 \mathrm{mM}$ gemfibrozil (for 1-3 h) (results not shown).

In order to go deeper into the GFZ molecular 
Table 2. Effect of concentration of orthovanadate and gemfibrozil on the rates of sulfate transport of oxygenated human adult red blood cells. ( $p<0.05$ was considered significant).

\begin{tabular}{lc} 
Conditions & $\begin{array}{c}\text { Rate constant } \\
\left(\mathbf{m i n}^{-\mathbf{1}}\right)\end{array}$ \\
\hline Control & $0.012 \pm 0.0026(n=4)$ \\
3mM orthovanadate & $0.018 \pm 0.0037(n=4)$ \\
3mM gemfibrozil & $0.052 \pm 0.0014(n=4)$ \\
3mM orthovanadate and & $0.032 \pm 0.0051(n=5)$ \\
3mM gemfibrozil & \\
\hline
\end{tabular}

effect we performed a set of experiments on the anionic exchange in the presence of orthovanadate, a well-known phosphatase inhibitor which affects the phosphorylation/dephosphorylation state of B3. Kinetic measurements carried out on erythrocytes with $3 \mathrm{mM}$ orthovanadate exhibit a modest increment of the B3 activity; these results were compared with those obtained with gemfibrozil. This comparison is reported in Table 2. The different modulation intensity of the anionic flux in response to orthovanadate and gemfibrozil and the absence of an effect of the latter on PTP-1B phosphatase activity allowed us to exclude a GFZ involvement on the phosphorylation state of the erythrocyte membrane. However, in order to better evaluate the results we carried out further kinetic experiments estimating the combined effects of orthovanadate and gemfibrozil.

The rate constant value measured under these conditions, the index of increment not being cumulative, indicated an effective role of fibrate, certainly connected with $\mathrm{cdb} 3$, the latter being the target of orthovanadate phosphorylation.

To confirm this hypothesis we used erythrocytes (chicken erythrocytes) characterized by B3 modified at the level of the cytoplasmic domain (Jay 1983). The chicken (Gallus gallus) red blood cells have been incubated in the presence and absence of $3 \mathrm{mM}$ gemfibrozil; under the two experimental conditions the rate constant values were not significantly different $\left(0.070 \pm 0.019 \mathrm{~min}^{-1}\right.$ and $0.068 \pm 0.004 \mathrm{~min}^{-1}$, respectively) indicating cdb3 as the fundamental target through which GFZ exercises its effect.

\section{Discussion}

In our previous studies (Galtieri et al. 2002, Russo et al. 2007) it was demonstrated that the anionic

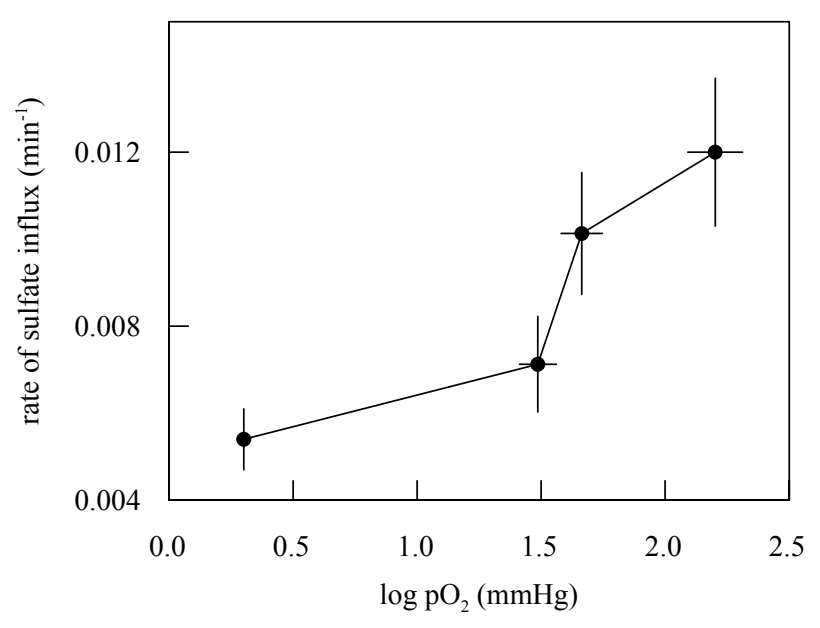

Fig. 4. Rates of sulfate influx determined in human erythrocytes under different oxygen pressure. For experimental conditions see Methods. Rates are reported in $\min ^{-1}$ and $\mathrm{pO}_{2}$ values in $\mathrm{mmHg}$.

flux across the B3 is oxygen-dependent and is connected to the T-R conformational transition of $\mathrm{Hb}$ as also outlined by data reported in Fig. 4. From these a role of gemfibrozil in the anionic flux modulation clearly emerges; the drug seems to have a "stimulating" action on the B3 activity that is much greater when the erythrocyte is at high oxygen saturation (HOS) conditions and less important in the LOS state. Experiments performed on the ghosts suggest that $\mathrm{cdb} 3$ is the main GFZ target; in fact, the observed effect can be attributed exclusively to the presence of gemfibrozil since these structures lack all the main cellular components and possible anionic transport mediators.

The results obtained may be interpreted on the basis of the strong interaction of GFZ with one of the main modulators of B3, hemoglobin. In this respect it should be recalled that X-ray crystallographic analysis demonstrated that two molecules of bezafibrate (BZF) bind to the central cavity of deoxy-Hb in a symmetrical fashion (Abraham et al. 1983) and that the BZF molecule which is structurally very similar to gemfibrozil, interacts with human $\mathrm{Hb}(\mathrm{HbA})$ not only in the $\mathrm{T}$ conformational state (Perutz et al. 1986, Noble et al. 1989, Bettati et al. 1997) but surprisingly also in the R state (Shibayama et al. 2002). Moreover, recent modeling studies showed specific binding sites both in the $\mathrm{T}$ state and in the $\mathrm{R}$ state of $\mathrm{HbA}$ not only for BPG and inositol hexaphosphate (IHP) but also for clofibrate and BZF analogs (Laberge et al. 2005).

Due to the higher affinity of $\mathrm{T}-\mathrm{Hb}$ for $\mathrm{cdb} 3$ compared to $\mathrm{R}-\mathrm{Hb}$ a gradual increase of bound hemoglobin and, consequently, an increase of structural 
hindrance occur on going from HOS to LOS (Galtieri et al. 2002). Thus in the LOS of erythrocytes the Hb-GFZ complex, strongly interacting with $\mathrm{cdb} 3$, may cause a structural hindrance of band 3 channel and, consequently, a decrease of anionic flux through the membrane.

In addition, BZF, a molecule similar to gemfibrozil, is bound to $\mathrm{Hb}$ in the $\mathrm{Z}$ and $\mathrm{R}$ state not only at different sites but also at sites involving several numerical interactions (Perutz et al. 1986, Shibayama et al. 2002).

In this context the different modulation of the anionic flux observed in HOS and LOS states of the erythrocyte could be associated with the different binding free energy in the T-Hb-GFZ-cdb3 and R-Hb-GFZ-cdb3 complexes.

Deoxyhemoglobin binds the cdb3 by means of a series of electrostatic interactions (Jensen et al.1998) with the first $11 \mathrm{~N}$-terminal residues of the anionic exchanger; such a binding is influenced by the oxygenation state of erythrocyte ( $K_{\text {ass }}$ approximately $\left.4 \times 10^{-4} \mathrm{M}\right)$ (Chetrite et al. 1985). Hence, the remarkable difference in the anionic flux across B3, measured in red blood cell HOS and LOS states, could be ascribed to the various modes of binding of GFZ with $\mathrm{Hb}$ in the $\mathrm{T}$ and $\mathrm{R}$ conformational states (supported by the significant difference of $K_{\text {ass }}$ between $\mathrm{Hb}$ and $\mathrm{B} 3$ on the oxygenation state).

The results could be interpreted in the light of the recent theory of the "global allostery model" which supposes that the allosteric effectors can bind to both the T and to $\mathrm{R}$ states of the $\mathrm{Hb}$ inducing direct tertiary conformational changes of the structure that can provoke remarkable variations of hemoglobin function (Yonetani et al. 2002, Shibayama et al. 2002, Laberge et al. 2005).

The anionic flux increase induced by the GFZ in the LOS state should be a positive physiological aspect because it may allow a more efficient $\mathrm{CO}_{2}$ exchange (produced also "exogenously" through 6-phosphogluconate oxidation). However, a better analysis of RBC metabolism demonstrated a negative influence induced by the drug on the oxidative status of the cell.

In fact, the GFZ binding to $\mathrm{Hb}$ reduced remarkably the oxygen-binding affinity and delayed the separation from cdb3. This would cause a late binding of glycolytic enzymes to B3, extending the EMP pathway at the expense of NADPH production necessary to neutralize the oxygen radicals and to reduce the level of ferrihemoglobin. In other words, under these circumstances the GFZ would contribute significantly to the erythrocyte oxidative stress.
Hence, the interaction of GFZ with $\mathrm{Hb}$ may cause unexpected functional responses, such as those observed by Tsuneshige et al. (2002), Shibayama et al. (2002) and, significantly, by Coletta et al. (1999) where the addition of BZF to stripped $\mathrm{Hb}$ lowers the oxygen affinity of the Rstate hemoglobin by a factor of $8-10$ at $\mathrm{pH}$ 7.0. The HbGFZ complex with new structural and functional characteristics, will be able to bind cdb3 even when hemoglobin is in its oxygenated state.

In this context the different modulation of the anionic flux observed here in HOS and LOS states of the erythrocyte could be tied to the different binding free energy in the complexes T-Hb-GFZ-cdb3 and R-Hb-GFZcdb3. In other words GFZ would interact with $\mathrm{Hb}$ and therefore with the whole complex with a binding free energy very different in the HOS and LOS states of the red blood cell. This consideration is supported by the different fibric effector stoichiometry in the $\mathrm{T}$ and $\mathrm{R}$ state of $\mathrm{Hb}$ (Laberge et al. 2005).

In summary, binding of GFZ to intraerythrocytic hemoglobin, besides decreasing the oxygen affinity of the cell, results in a substantial alteration of the oxygen-linked metabolic modulation since it makes the $\mathrm{R}$ state able to bind the cytoplasmic domain of band 3 . This would greatly favor glycolysis with respect to the pentose shunt decreasing NADPH production and therefore the overall reducing power of the cell. On this basis we may say that erythrocytes treated with GFZ could be much more prone towards oxidative stress than normal untreated cells.

Last but not least, it is worthwhile to consider that the strong modification of anion transport at the level of band 3 by the gemfibrozil-hemoglobin complex could represent a useful model to further investigate other neglected aspects of peripheral oxygen delivery, such as (a) the role of oxy-Hb in modulating isohydric transport and chloride shift at band 3 level, (b) the potential interplay between band 3 oxy-Hb and nitric oxide transport and release and (c) the reciprocal modulation between carbonate dehydratase II and oxy-Hb at the level of band 3 binding sites.

\section{Conflict of Interest}

There is no conflict of interest.

\section{Acknowledgements}

The work of the Italian authors was supported by the Plan Search Athenaeum agency, that of the Czech author (A. Kotyk) by research grant IET 400110403 from the Grant Agency of the Czech Republic. 


\section{References}

ABRAHAM DJ, PERUTZ MF, PHILLIPS SEV: Physiological and X-ray studies of potential antisickling agents. Proc Natl Acad Sci USA 80: 324-328, 1983.

BENNETT V: The membrane skeleton of human erythrocytes and its implications for more complex cells. Annu Rev Biochem 54: 273-304, 1985.

BETTATI S, MOZZARELLI A: T state hemoglobin binds oxygen noncooperatively with allosteric effects of protons, inositol hexaphosphate, and chloride. J Biol Chem 272: 32050-32055, 1997.

BROWN MS, GOLDSTEIN JL: Atherosclerosis. Scavenging for receptors. Nature 343: 508-509, 1990.

BRUNATI AM, BORDIN L, CLARI G, JAMES P, QUADRONI M, BARITONO E, PINNA LA, DONELLA-DEANA A: Sequential phosphorylation of protein band 3 by Syk and Lyn tyrosine kinases in intact human erythrocytes: identification of primary and secondary phosphorylation sites. Blood 96: 1550-1557, 2000.

CAMPANELLA ME, CHU H, LOW PS: Assembly and regulation of a glycolytic enzyme complex on the human erythrocyte membrane. Proc Natl Acad Sci USA 102: 2402-2407, 2005.

CHANCE DS, MCINTOSH MK: Hypolipidemic agent alter hepatic mitochondrial respiration in vitro. Comp Biochem Physiol C Pharmacol Toxicol Endocrinol 111: 317-323, 1995.

CHETRITE G, CASSOLY R: Affinity of hemoglobin for the cytoplasmic fragment of human erythrocyte membrane band 3. Equilibrium measurements at physiological $\mathrm{pH}$ using matrix-bound proteins: the effects of ionic strength, deoxygenation and of 2,3-diphosphoglycerate. J Mol Biol 185: 639-644, 1985.

CHU H, LOW PS: Mapping of glycolytic enzyme-binding sites on human erythrocyte band 3. Biochem J 400: 143-151, 2006.

COLETTA M, ANGELETTI M, ASCENZI P, BERTOLLINI A, Della LONGA S, De SANCTIS G, PRIORI AM, SANTUCCI R, AMICONI G: Coupling of the oxygen-linked interaction energy for inositol hexakisphosphate and bezafibrate binding to human HbA0. J Biol Chem 274: 6865-6874, 1999.

FRICK MH, ELO O, HAAPA K, HEININEN OP, HEINSALMI P, HELO P, HUTTUNEN JK, KAITANIENI P, KOSKINENP, MANNINEN V: Helsinki Heart Study: primary-prevention trial with gemfibrozil in middleaged men with dyslipidemia. Safety of treatment, changes in risk factors, and incidence of coronary heart disease. $N$ Engl J Med 317: 1237-1234, 1987.

GALTIERI A, TELLONE E, ROMANO L, MISITI F, BELLOCCO E, FICARRA S, RUSSO A, Di ROSA D, CASTAGNOLA M, GIARDINA B, MESSANA I: Band-3 protein function in human erythrocytes: effect of oxygenation-deoxygenation. Biochim Biophys Acta 1564: 214-218, 2002.

GIARDINA B, MESSANA I, SCATENA R, CASTAGNOLA M: The multiple functions of hemoglobin. Crit Rev Biochem Mol Biol 30: 165-196, 1995.

GOODALL HB, REID AH, FINDLAY DJ, HIND C, KAY J AND COGHILL G: Irregular distortion of the erythrocytes (acanthocytes, spur cells) in senile dementia. Dis Mark 12: 23-41, 1994.

HAN BG, NUNOMUR WA, TAKAKUWA Y, MOHANDAS N, JAP BK: Protein 4.1 core domain structure and insights into regulation of cytoskeletal organization. Nat Struct Biol 7: 871-875, 2000.

HARRIS SJ, WINZOR DJ: Interaction of glycolytic enzymes with erythrocyte membranes. Biochim Biophys Acta 1038: 306-314, 1990.

HARRISON ML, ISAACSON CC, BURG DL, GEAHLEN RL, LOW PS: Phosphorylation of human erythrocyte band 3 endogenus p72syk. J Biol Chem 269: 955-959, 1994.

HYDE RM, LIVINGSTONE DJ, PATTERSON RA, BATCHELOR JF, KING WR: Modification of the haemoglobin oxygen dissociation curve in whole blood by a compound with dual action. Lancet 2: 15-16, 1984.

IMAI K, TSUNESHIGE A, YONETANI T: Description of hemoglobin oxygenation under universal solution conditions by a global allostery model with a single adjustable parameter. Biophys Chem 98: 79-91, 2002.

JAY DG: Characterization of the chicken erythrocyte anion exchange protein. $J$ Biol Chem 258: 9431-9436, 1983.

JENSEN FB, JAKOBSEN MH, WEBER RE: Interaction between haemoglobin and synthetic peptides of the Nterminal fragment of trout band 3 (AE1) protein. J Exp Biol 201: 2685-2690, 1998.

JIANG W, DING Y, SU Y, JIANG M, HU X, ZHANG Z: Interaction of glucose transporter 1 with anion exchanger 1 in vitro. Biochem Biophys Res Comm 339: 1255-1261, 2006. 
KLIMAN HJ, STECK TL: Association of glyceraldehyde-3-phosphate dehydrogenase with the human red cell membrane. A kinetic analysis. J Biol Chem 255: 6314-6321, 1980.

KORSGREN C, COHEN CM: Purification and properties of human erythrocyte band 4.2. Association with the cytoplasmic domain of band 3. J Biol Chem 261: 5536-5543, 1986.

LABERGE M, KOVESI I, YONETANI T, FIDY J: R-state hemoglobin bound to heterotropic effectors: model of the DPG, IHP, and RSR 13 binding sites. FEBS Lett 579: 627-635, 2005.

LABOTKA RJ: Measurement of intracellular $\mathrm{pH}$ and deoxyhemoglobin concentration in deoxygenated erythrocytes by phosphorus-31 nuclear magnetic resonance. Biochemistry 23: 5549-5555, 1984.

LALEZARI I, LALEZARI P, POYART C, MARDEN M, KISTER J, BOHN B, FERMI G, PERUTZ MF: New effectors of human hemoglobin: structure and function. Biochemistry 29: 1515-1523, 1990.

LOW PS: Structure and function of the cytoplasmic domain of band 3: center of erythrocyte membrane-peripheral protein interactions. Biochim Biophys Acta 864: 145-167, 1986.

LOW PS, WILLARDSON BM, MOHANDAS N, ROSSI M, SHOHET S: Contribution of the band 3-ankyrin interaction to erythrocyte membrane mechanical stability. Blood 77: 1581-1586, 1991.

MANNINEN V, ELO MO, FRICK MH, HAAPA K, HEINONEN OP, HEINSALMI P, HELO P, HUTTUNEN JK, KAITANIEMI P, KOSKINEN P: Lipid alterations and decline in the Helsinki Heart Study. JAMA 260: 641$651,1988$.

MARDEN MC, KISTER J, BOHN B, POYART C: T-state hemoglobin with four ligands bound. Biochemistry 27: 1659-1664, 1988.

MESSANA I, ORLANDO M, CASSIANO L, PENNACCHIETTI L, ZUPPI C, CASTAGNOLA M, GIARDINA B: Human erythrocyte metabolism is modulated by the O2-linked transition of hemoglobin. FEBS Lett 390: 2528, 1996.

MURTHY SN, LIU T, KAUL RK, KOHLER H, STECK TL: The aldolase-binding site of the human erythrocyte membrane is at the NH2 terminus of band 3. J Biol Chem 256: 11203-11208, 1981.

NOBLE RW, De YOUNG A, VITALE S, CERDONIO M, Di IORIO EE: Spin equilibria in human methemoglobin: effects of bezafibrate and inositol hexaphosphate as measured by susceptometry and visible spectroscopy. Biochemistry 28: 5288-5292, 1989.

PERUTZ MF, POYART C: Bezafibrate lowers oxygen affinity of hemoglobin. Lancet 2: 881-882, 1983.

PERUTZ MF, FERMI G, ABRAHAM D J, POYART C, BURSAUX E: Hemoglobin as a receptor of drugs and peptides: X-ray studies of the stereochemistry of binding. J Am Chem Soc 108: 1064-1078, 1986.

POYART C, MARDEN MC, KISTER J: Bezafibrate derivatives as potent effectors of hemoglobin. Methods Enzymol 232: 496-513, 1994.

ROMANO L, PERITORE D, SIMONE E, SIDOTI A, TRISCHITTA F, ROMANO P: Chloride-sulphate exchange chemically measured in human erythrocyte ghosts. Cell Mol Biol 44: 351-355, 1998.

RUSSO A, TELlONE E, FICARRA S, GIARDINA B, BELlOCCO E, LAGANA G, LEUZZI U, KOTYK A, GALTIERI A: Band 3 protein function in teleost fish erythrocytes: effect of oxygenation-deoxygenation. Physiol Res 57: 49-54, 2008.

SAFO MK, BOYIRI T, BURNETT JC, DANSO-DANQUAH R, MOURE CM, JOSHI GS, ABRAHAM DJ: X-ray crystallographic analyses of symmetrical allosteric effectors of hemoglobin: compounds designed to link primary and secondary binding sites. Acta Crystallogr D Biol Crystallogr 58: 634-644, 2002.

SALHANY JM: Erythocyte Band 3 Protein. CRC Press, Boca Raton, 1990.

SCATENA R, NOCCA G, MESSANA I, DE SOLE P, BARONI S, ZUPPI C, CASTAGNOLA M, GIARDINA B: Effects of gemfibrozil on the oxygen transport properties of erythrocytes J Clin Pharmacol 39: 25-30, 1995.

SHIBAYAMA N, MIURA S, TAME JRH, YONETANI T, PARK SY: Crystal structure of horse carbonmonoxyhemoglobin-bezafibrate complex at 1.55-A resolution. J Biol Chem 277: 38791-38796, 2002.

TSUNESHIGE A, PARK S, YONETANI T: Heterotropic effectors control the hemoglobin function by interacting with its $\mathrm{T}$ and R states - a new view on the principle of allostery. Biophys Chem 98: 49-63, 2002.

TSUNESHIGE A, KANAORI K, SAMUNI U, DANSTKER D, FRIEDMAN JM, NEYA S, GIANGIACOMO L, YONETANI T: Semihemoglobins: high oxygen affinity dimeric forms of human hemoglobin respond efficiently to allosteric effectors without forming tetramers. J Biol Chem 279: 48959-48967, 2004. 
WALDER JA, CHATTERJEE R, STECK TL, LOW PS, MUSSO GF, KAISER ET, ROGERS PH, ARNONE A: The interaction of hemoglobin with the cytoplasmic domain of band 3 of the human erythrocyte membrane. $J$ Biol Chem 259: 10238-10246, 1984.

WEBER R E, VOELTER W, FAGO A, ECHNER H, CAMPANELLA E, LOW PS: Modulation of red cell glycolysis: interactions between vertebrate hemoglobins and cytoplasmic domains of band 3 red cell membrane proteins. Am J Physiol 287: R454-R464, 2004.

YONETANI T, PARK QS, TSUNESHIGE A IMAI K, KANAORI K: Global allostery model of hemoglobin: modulation of $\mathrm{O}_{2}$ affinity, cooperativity, and Bohr effect by heterotropic allosteric effectors. J Biol Chem 277 : 34508-34520, 2002.

ZIJLSTRA WG, BUURSMA A, MEEUWSEN-VAN DER ROEST WP: Absorption spectra of human fetal and adult oxyhemoglobin, deoxyhemoglobin, carboxyhemoglobin and methemoglobin. Clin Chem 37: 1633-1638, 1991.

ZIPSER Y, KOSOVER NS: Phosphotyrosine phosphatase associated with band 3 protein in human erythrocyte membrane. Biochem J 314: 881-887, 1996. 